\title{
HPV Vaccination in Young Girls from Developing Countries: What Are the Barriers for Its Implementation? A Systematic Review
}

\author{
Inês Maria Brito Gonçalves', Joana Rafaela Magalhães Fernandes ${ }^{1}$, Filipa Ribeiro ${ }^{1,2}$, \\ Adhemar Longatto-Filho ${ }^{1,2,3,4,5^{*}}$
}

${ }^{1}$ School of Medicine, University of Minho, Braga, Portugal

${ }^{2}$ Life and Health Sciences Research Institute (ICVS), School of Medicine, University of Minho, Braga, Portugal

${ }^{3}$ ICVS/3B's-PT Government Associate Laboratory, Braga/Guimarães, Portugal

${ }^{4}$ Molecular Oncology Research Center, Barretos Cancer Hospital, Barretos, São Paulo, Brazil

${ }^{5}$ Medical Laboratory of Medical Investigation (LIM) 14, Department of Pathology, Medical School, University of São Paulo,

São Paulo, Brazil

Email: *longatto@med.uminho.pt

How to cite this paper: Gonçalves, I.M.B., Fernandes, J.R.M., Ribeiro, F. and Longatto-Filho, A. (2020) HPV Vaccination in Young Girls from Developing Countries: What Are the Barriers for Its Implementation? A Systematic Review. Health, 12, 671-693.

https://doi.org/10.4236/health.2020.126050

Received: May 21, 2019

Accepted: June 26, 2020

Published: June 29, 2020

Copyright $\odot 2020$ by author(s) and Scientific Research Publishing Inc. This work is licensed under the Creative Commons Attribution International License (CC BY 4.0).

http://creativecommons.org/licenses/by/4.0/

\section{(c) (i) Open Access}

\begin{abstract}
Cervical cancer is the second most common cancer in women living in developing countries that account high HPV incidence and mortality rates. Vaccinating girls between 9 and 14 years old is supposed to be the most cost-effective public health approach against cervical cancer. This systematic review aims to assess the application and coverage of the HPV vaccine in developing countries and identify the main challenges for the introduction of the vaccine in these settings. Eligible studies were selected according to the defined inclusion and exclusion criteria. To determine the quality of the studies was employed the STROBE checklist. This review included seven studies, encompassing the analysis of 19 countries and 112,116 girls aged from 9 to 18 years old. The coverage of HPV vaccination ranged from $13.8 \%$ to $107.4 \%$, with most of the programs having more than $60 \%$ of coverage, which reflects a high percentage of vaccinated girls. The main challenges were lack of knowledge and worries about the vaccine, insufficient financial resources and staff workers, lack of community involvement and dissemination of important information about HPV. In developing countries that implemented the HPV vaccine, high coverage rates were achieved, despite sociocultural, economic and political challenges. In the future, studies that analyze the coverage rates after the elimination of the barriers and the repercussions on the mortality rates should be conducted, so that more developing countries have the opportunity to efficiently implement the vaccine.
\end{abstract}




\section{Keywords}

HPV Vaccine, HPV Knowledge and Education, HPV-Induced Cancer, Papillomavirus Vaccine Awareness, Cervical Cancer Mortality, HPV Incidence, HPV in Developing Countries

\section{Introduction}

Human papillomavirus (HPV) is family of almost 200 viruses' types; most of them cause highly common viral infection of the female reproductive tract. It's mainly transmitted through sexual contact and most people are infected with HPV shortly after the onset of sexual activity [1]. Many types of HPV don't cause health complications. However, infections with the high-risk HPV types can persist and progress to cervical cancer; among these high-risk types, HPV16 and HPV18, are responsible for $70 \%$ of cervical cancers and precancerous cervical lesions. In 2018, 570,000 women developed cervical cancer and 311,000 died from it. Nowadays, it's the second most common cancer in women living in developing regions [1]. Approximately $84 \%$ of all cervical cancers and $88 \%$ of all deaths caused by this cancer occurred in lower-resource countries [2].

It's, therefore, a serious health problem, which reflects the need to adopt stringent preventive and control measures. The main procedures involve primary prevention (HPV vaccine), secondary prevention (cytological or molecular HPV testing screening) and tertiary prevention (diagnosis and treatment of invasive cervical cancer) [1]. Most of these public health attitudes allowed developed countries to decrease the incidence and mortality rates from HPV. However, this isn't the scenario for developing countries as these sites have limited medical contact and poor infrastructures to adequate prevention and control measures, which leads to cervical cancers being diagnosed at very advanced stages, without the possibility of effective treatment ${ }^{1}$. Protection against HPV infection and cervical cancer is such pertinent public health assertiveness that, since 2009, WHO recommends the introduction of HPV vaccine in national immunization programs [3]. In fact, vaccinating girls between 9 and 14 years old is assumed as the most cost-effective public health intervention against cervical cancer [1]. Currently, there are 3 prophylactic vaccines that protect against infections caused by HPV 16 and 18, other oncogenic HPVs and two non-oncogenic HPV (Table 1). Clinical trials and post-marketing surveillance showed significant evidence that these vaccines are safe and effective. Despite the fact that they protect against others additional HPV types besides 16 and 18, WHO considers that all 3 equally prevent cervical cancer [4] [5]. From 2009 to 2018, over 80 countries have implemented these vaccines in their immunization programs, but the majority was applied in developed countries. Developing countries, which have the highest burden of cervical cancer and the most need for vaccination, are still the ones with more barriers in the introduction of the vaccine [6]. Financial 
Table 1. Main characteristics of the three HPV vaccines according to WHO recommendations in Guide to introducing HPV Vaccine into National Immunization Programmes (2016).

\begin{tabular}{|c|c|c|c|}
\hline ATTRIBUTES & BIVALENT (CERVARIX ${ }^{\circledR}$ ) & $\begin{array}{c}\text { QUADRIVALENT } \\
\text { (GARDASIL }^{\circledast} / \text { SILGARD }^{\circledR} \text { ) }\end{array}$ & 9-VALENT (GARDASIL $9^{\circledR}$ ) \\
\hline Vaccine type & $\begin{array}{l}\text { Recombinant L1-capsid } \\
\text { virus-like particles (VLP) }\end{array}$ & $\begin{array}{l}\text { Recombinant L1-capsid } \\
\text { virus-like particles (VLP) }\end{array}$ & $\begin{array}{l}\text { Recombinant L1-capsid } \\
\text { virus-like particles (VLP) }\end{array}$ \\
\hline HPV types & 16,18 & $6,11,16,18$ & $6,11,16,1831,33,45,52,58$ \\
\hline Disease protection & $\begin{array}{l}\text { Cervical cancer (and premalignant } \\
\text { genital lesions of cervix, } \\
\text { vulva and vagina) }\end{array}$ & $\begin{array}{c}\text { Cervical cancer (and premalignant } \\
\text { genital lesions of cervix, vulva and } \\
\text { vagina), Genital warts }\end{array}$ & $\begin{array}{l}\text { Cervical cancer (and premalignant } \\
\text { genital lesions of cervix, vulva } \\
\text { and vagina), Genital warts }\end{array}$ \\
\hline Age of vaccination & $9-14$ & $9-13$ & $9-14$ \\
\hline $\begin{array}{c}\text { Number of doses } \\
\text { required }\end{array}$ & 2 & 2 & 2 \\
\hline Dosing interval & $\begin{array}{l}0 \text { and } 6 \text { months (No maximum } \\
\text { interval but suggested not } \\
\text { more than } 12-15 \text { months) }\end{array}$ & $\begin{array}{l}0 \text { and } 6 \text { months (No maximum } \\
\text { interval but suggested not } \\
\text { more than } 12-15 \text { months) }\end{array}$ & $\begin{array}{l}0 \text { and } 6 \text { months (No maximum } \\
\text { interval but suggested not } \\
\text { more than } 12-15 \text { months) }\end{array}$ \\
\hline
\end{tabular}

supports from several institutions based on demonstration projects were implemented by like Gavi (Vaccine Alliance), which nowadays funds the majority of these projects to increase access to HPV vaccine worldwide [5] [6]. Thus, it's important to assess the application and coverage of the HPV vaccine after the efforts made by organizations and to identify the main challenges that developing countries are facing. Herein we aimed to investigated, using a systematic review model, the difficulties and inequalities related to the HPV vaccine introduction, and discuss potential actions to optimize aid and maximize the access to HPV vaccines, improving the prevention of HPV-induced cervical cancer. We also sought to evaluate the percentage of application of HPV vaccination in girls between 9 and 14 years old in developing countries; and identify the main challenges in the implementation of HPV vaccine in developing countries.

\section{Methods}

In order to enable a good data collection and, consequently, its analysis, this systematic review was based on a set of defined objectives, as well as a set of inclusion and exclusion criteria.

\section{Search Strategy}

Until 16 March 2020, we searched in two electronic databases, PubMed and Scopus, for relevant articles, since 10 years ago. Through the combination of keywords (HPV OR "Human Papillomavirus") AND (Vaccine or Vaccination) AND ("Developing countries" OR "Low and middle-income countries") appearing in titles and abstracts, these databases presented a list of possible studies. Then, we selected the articles according to the type of study, title, abstract and full text in a sequential way. 


\section{Criteria for Study Selection}

\subsection{Inclusion Criteria}

1) Girls aged 9 - 14 years (age group for whom WHO recommends HPV vaccination);

2) Studies on developing countries with implementation of HPV vaccine;

3) Studies that address challenges for vaccine implementation;

4) Observational studies;

5) Studies published since 2010 (as HPV vaccination was recommended by WHO since 2009).

\subsection{Exclusion Criteria}

1) Studies with indistinct selection criteria;

2) Case-reports, systematic reviews and meta-analysis;

3) Duplicated studies;

4) Non-Portuguese and non-English written studies;

5) Unavailable full text articles.

\section{Data Collection and Analysis}

\subsection{Studies Selection}

After the initial research, it was necessary to remove all the duplicated studies and to evaluate the titles and abstracts of the remaining articles, according to the inclusion and exclusion criteria. These elements were evaluated to remove studies that were not clearly related to the topic and to determine their relevance. This process involved two researchers to minimize bias and to ensure that important articles were not excluded. To assure that, the researchers decided to extend the age range defined in the inclusion criteria to girls between 9 and 18 years old, in order to include a number of articles considered important to this review. Disagreements were resolved by critical discussion and consensus. When the title and abstract left doubts about the relevance of the articles, the full text had to be read. In order to select properly the articles, two tools were used, Mendeley to remove the duplicated studies and Excel ${ }^{\mathrm{Tm}}$ to exclude the articles, according the criteria.

\subsection{Data Extraction and Management}

After reviewing the full text of the selected studies, it was extracted data such as the authors names; year of publication; type of study; population characteristics (gender, age, sociocultural characteristics); country where the study was performed and outcomes concerning the percentage of coverage of HPV vaccination (relative proportion of girls with a full-course of vaccination to the total number of girls originally targeted by the program) and the barriers and challenges of its implementation.

The same two researchers, onto an Excel sheet to display all relevant informa- 
tion in an organized manner and to compare the results of the evaluated outcomes, collected these data independently. Disagreement on findings were discussed and resolved by face-to-face critical discussion.

\subsection{Assessment of Quality of the Studies}

To determine the quality of observational studies was employed the STROBE (Strengthening the Reporting of Observational Studies in Epidemiology) checklist combined. To determine the quality of cross-sectional studies was employed the STROBE checklist to cross-sectional articles. Both checklists were available in https://www.equator-network.org/reporting-guidelines/strobe/. Each item of the statement had the same weight. Whenever an item was checked in the article, 2 points, that corresponded to the color green, were awarded; if the study only had part of the information requested, 1 point, which corresponded to the color yellow, was awarded; if an item wasn't present in the study, 0 points, that corresponded to the color red, were assigned. The items that weren't applicable in the studies were colored grey and didn't enter the account of the maximum score. Studies were classified as high quality if they had more than $75 \%$ of the maximum score possible; as moderate quality if they had about to $50 \%$ to $75 \%$ of the maximum score possible and as low quality if they had less than $50 \%$ of the maximum score possible.

\section{Results}

\subsection{Literature Search and Selection}

The search in PubMed and Scopus with the words "HPV", "human papillomavirus", "vaccine", "vaccination", "and developing countries" and "low and middle-income countries" resulted in 814 articles since 2010 (presented in the PRISMA Flowchart [7] in Figure 1). Of these, 342 articles were excluded for being duplicates. In the first screening, 16 articles were readily removed for access not allowed and for being in other languages than Portuguese or English. After the read of the titles and abstracts, more were excluded for being systematic reviews or other types of documents that weren't included (like reviews, case reports, editorials, chapters of books, comments); for not addressing developing countries and for being related to other topics besides HPV vaccine application and its barriers.

Thereby, were removed 452 articles with 20 remaining for full reading. Of these studies, only 7 were included in this systematic review, because they had clear selection criteria. The two outcomes of interest: percentage of HPV vaccination application and challenges in its implementation; and study population with the defined age range ( 9 to 18 years).

\subsection{Quality Appraisal}

Of the 7 studies included in this review, $28.6 \%$ were classified as moderate to high quality, $57.1 \%$ were ranked as moderate quality, $14.3 \%$ were classified as 


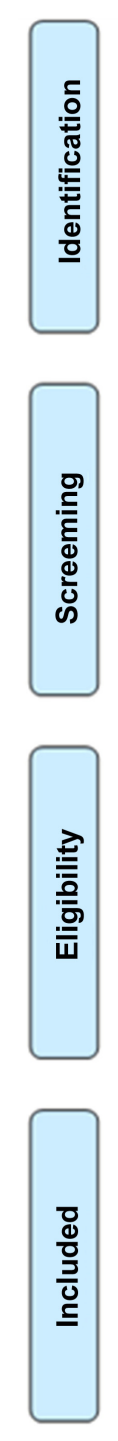

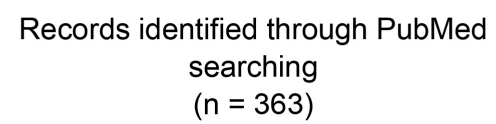

Additional records identified through

Scopus searching

$(n=451)$

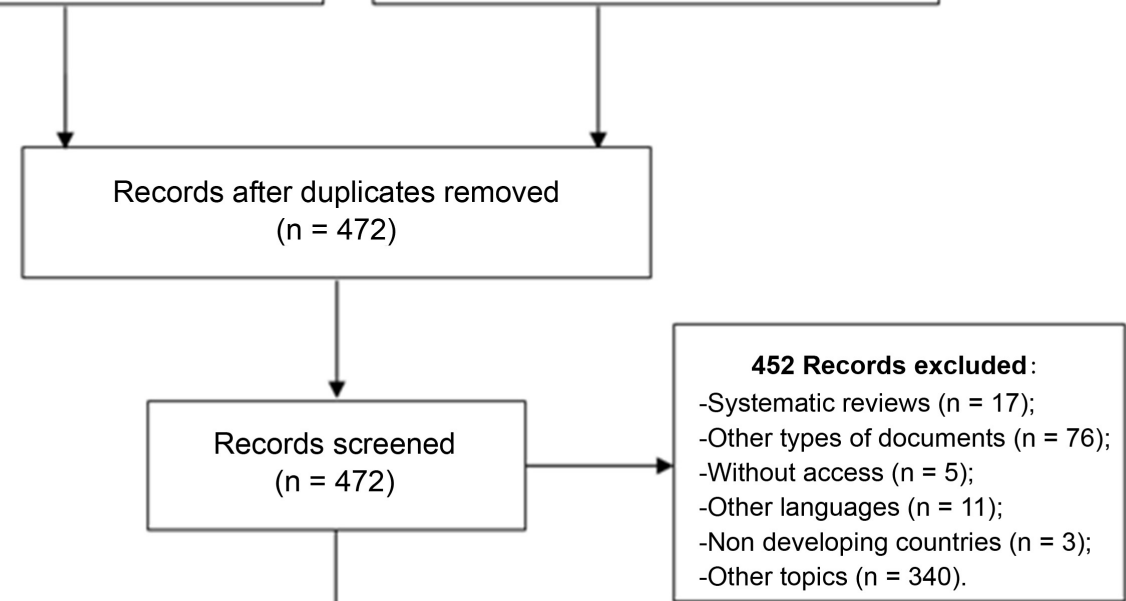

Figure 1. PRISMA Flowchart sequence used in this study.

moderate to low quality and none of the selected articles were rated as low quality, exclusively. In the cross-sectional studies, the items with the lowest performance, in which no article reached the parameter, were $12 c, 12 \mathrm{e}, 13 \mathrm{c}$ and $14 \mathrm{~b}$, relative to statistical methods, participants of the study and descriptive data of results, respectively. In the observational studies, the items with the lowest performance, in which any of the articles achieved the parameter, were $9,12 c, 12 d$, $12 \mathrm{e}, 13 \mathrm{a}$ and $14 \mathrm{~b}$, that were relative to bias, statistical methods, participants of the study and descriptive data of results, respectively. Table 2 presents the quality parameters of the studies based on STROBE Checklist for Observational Studies (Table 2(a)) and STROBE Checklist for Cross-Sectional Studies (Table 2(b)).

\subsection{Description of the Studies}

We included seven articles, in which two were observational studies and five 


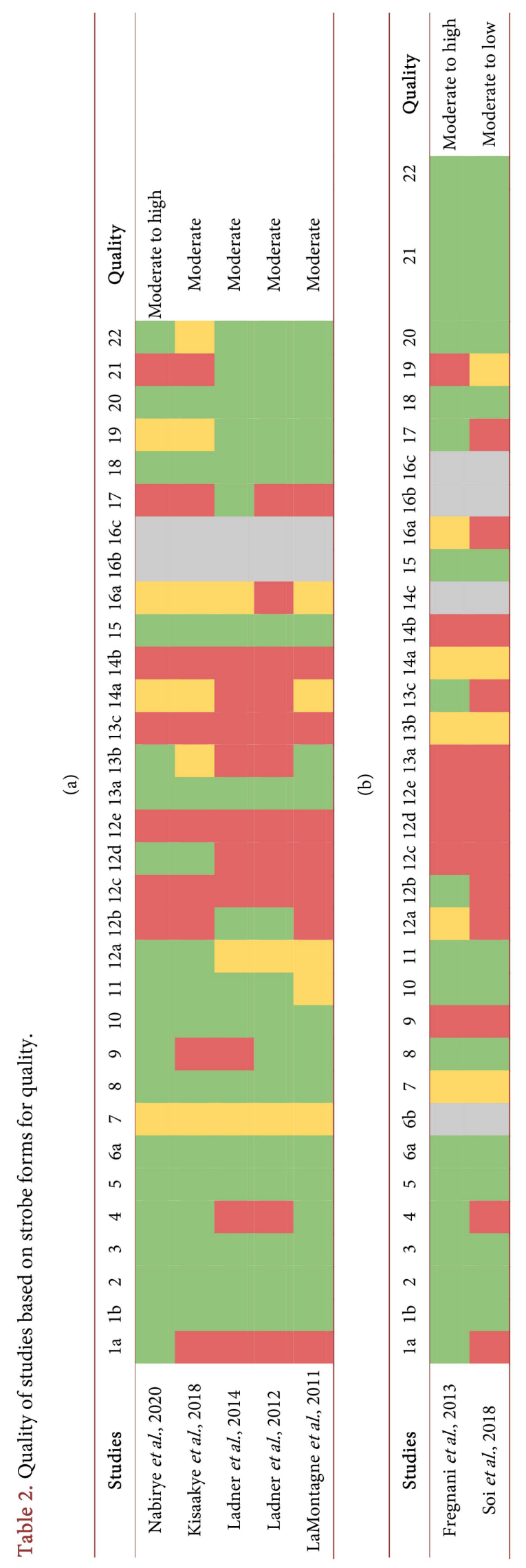


were cross-sectional studies (Table 3). All the articles were written in English. Six of the countries where the vaccination programs were implemented belong to Africa [8] [9] [10]; seven situate in Asia; three are in South America; one is located in Central America; one belongs to North America and two are in Europe. Almost all the continents were, therefore, represented in this review. The year of implementation of the vaccination program varied from 2008 to 2015, which coincides with the recommendations of WHO regarding the introduction of HPV vaccine in national immunization programs. All the articles aimed to assess the level of coverage and the factors influencing the HPV vaccination uptake in developing countries, except Soi et al., 2018 [10] that focuses more on the utility of the Consolidated Framework for Implementation Research (CFIR) in evaluating implementation barriers for the scale-up of interventions, namely HPV vaccination, in low and middle-income countries health systems.

Table 3. Summary of the main characteristics of the studies included in this review regarding HPV vaccination implementation and its barriers.

\begin{tabular}{|c|c|c|c|c|c|}
\hline $\begin{array}{l}\text { Authors } \\
\text { and Year }\end{array}$ & Type of Study & Language & Countries Analysed & $\begin{array}{l}\text { Year of } \\
\text { Implementation } \\
\text { of Vaccination } \\
\text { Program }\end{array}$ & Main objectives of the study \\
\hline $\begin{array}{l}\text { Nabirye et } \\
\text { al., } 2020^{8}\end{array}$ & $\begin{array}{c}\text { Observational } \\
\text { (cross-sectional) }\end{array}$ & English & Uganda & 2012 & $\begin{array}{l}\text { Aim to assess how the health system is influencing } \\
\text { uptake of the HPV vaccine for adolescents } 9-15 \\
\text { years and to inform HPV vaccination policy and } \\
\text { implementation program in Uganda. }\end{array}$ \\
\hline $\begin{array}{l}\text { Kisaakye et } \\
\text { al., } 2018^{9}\end{array}$ & $\begin{array}{l}\text { Observational } \\
\text { (cross-sectional) }\end{array}$ & English & Uganda & 2012 & $\begin{array}{l}\text { Assess the level and the factors associated with } \\
\text { uptake of HPV vaccine by female adolescent girls in } \\
\text { Lira district, Uganda to inform implementation of } \\
\text { the HPV vaccine program in Uganda. }\end{array}$ \\
\hline $\begin{array}{l}\text { Soi et al., } \\
2018^{10}\end{array}$ & Observational & English & Mozambique & 2015 & $\begin{array}{l}\text { Demonstrate the utility of CFIR in identifying and } \\
\text { documenting implementation barriers and } \\
\text { facilitators for the scale-up of interventions in low } \\
\text { and middle-income countries health systems. }\end{array}$ \\
\hline $\begin{array}{l}\text { Ladner et } \\
\text { al., 2014 }\end{array}$ & $\begin{array}{l}\text { Observational } \\
\text { (cross-sectional) }\end{array}$ & English & $\begin{array}{l}\text { Bhutan, Bolivia, Cambodia, Haiti, } \\
\text { Lesotho, Moldova, Uzbekistan, } \\
\text { Cameroon, Georgia, Nepal, } \\
\text { Tanzania, Uganda, Honduras and } \\
\text { Kenya }\end{array}$ & $\begin{array}{l}2009 \\
2010 \\
2011 \\
2012\end{array}$ & $\begin{array}{l}\text { Analyze performance factors in HPV vaccination } \\
\text { programs implemented in low and middle-income } \\
\text { countries. }\end{array}$ \\
\hline $\begin{array}{l}\text { Fregnani et } \\
\text { al., } 2013^{12}\end{array}$ & Observational & English & Brazil & $\begin{array}{l}2010 \\
2011\end{array}$ & $\begin{array}{l}\text { Evaluate the uptake and the three-dose completion } \\
\text { rates of a school-based HPV vaccination strategy in } \\
\text { a Brazilian city. }\end{array}$ \\
\hline $\begin{array}{l}\text { Ladner et } \\
\text { al., } 2012^{13}\end{array}$ & $\begin{array}{l}\text { Observational } \\
\text { (cross-sectional) }\end{array}$ & English & $\begin{array}{l}\text { Bhutan, Bolivia, Cambodia, } \\
\text { Cameroon, Haiti, Lesotho and } \\
\text { Nepal }\end{array}$ & $\begin{array}{l}2009 \\
2010\end{array}$ & $\begin{array}{l}\text { Describe the results of and key concerns in eight } \\
\text { HPV vaccination programs conducted in seven } \\
\text { lowest income countries. }\end{array}$ \\
\hline $\begin{array}{l}\text { La } \\
\text { Montagne } \\
\text { et al., } 2011^{14}\end{array}$ & $\begin{array}{l}\text { Observational } \\
\text { (cross-sectional) }\end{array}$ & English & India, Peru, Uganda and Vietnam & $\begin{array}{l}2008 \\
2009\end{array}$ & $\begin{array}{l}\text { Report the HPV vaccination coverage achieved and } \\
\text { the reasons that made individuals accept or decline } \\
\text { vaccination in order to assist government } \\
\text { deliberations on the introduction of HPV vaccine } \\
\text { programmes, particularly in low-resource settings. }\end{array}$ \\
\hline
\end{tabular}




\subsection{Description of the Study Population}

The population of the current review comprises 112,116 girls aged from 9 to 18 years old. This total number of participants doesn't include the girls that participate in the vaccination programs reported by Soi et al. [10], since this study doesn't specify the number of girls. The selection processes used by the seven studies were very distinctive, so they are made explicit in Table 4. Finally, concerning the sociocultural characteristics of the population evaluated, some of the main aspects addressed were the features of adolescents and their parents or guardians, religion, economic resources of the families, among others.

\subsection{The Application of HPV Vaccine}

The coverage of HPV vaccination, defined as the relative proportion of girls with a full-course of vaccination to the total number of girls originally targeted by the program, ranged from $13.8 \%$ to $107.4 \%$ (Table 5). The majority of the programs assessed had more than $60 \%$ of coverage, which reflects a high percentage of vaccinated girls, except in Mbale and Lira in Uganda [8] and Kisaakye et al. [9] and in Mocímboa da Praia in Mozambique [10]). For the implementation of the HPV vaccination, programs could use different types of delivery models: school-based, health-center-based and mixed delivery model. The choice of the model to be used depended on the proposed methodology by each vaccination program and had an important effect on coverage.

\subsection{The Challenges in HPV Vaccine Implementation}

The informations were collected through key informant interviews or questionnaires answered by the target girls or their parents and guardians. The presentation and content of informations concerning the challenges were different among the studies, since some only referred to individual factors or reasons for refusal, others reported challenges in a broader level and others referred to both (Table 6). Some of the main reasons given to refuse vaccination were: lack of awareness and knowledge about the HPV vaccine, worries about its safety and adverse effects, as well as mistrust and misbeliefs regarding the vaccine. The principal barriers addressed by the studies were insufficient financial resources and difficulties in the access and transportation, insufficient staff workers and inadequate training, inconsistency in vaccine supplies, lack of community involvement and dissemination of important information about the vaccine. Therefore, all the challenges referred in Table 6 showed a significant negative impact in the implementation of the HPV vaccine and its coverage.

\section{Discussion}

The results herein reported in this systematic review were primarily focused on the interest to evaluate the implementation of the HPV vaccine in developing countries, mostly through demonstration of different programs, in order to comprehend the existing barriers of HPV vaccine employment and recognize the 
Table 4. Description of the population of participants involved in each study.

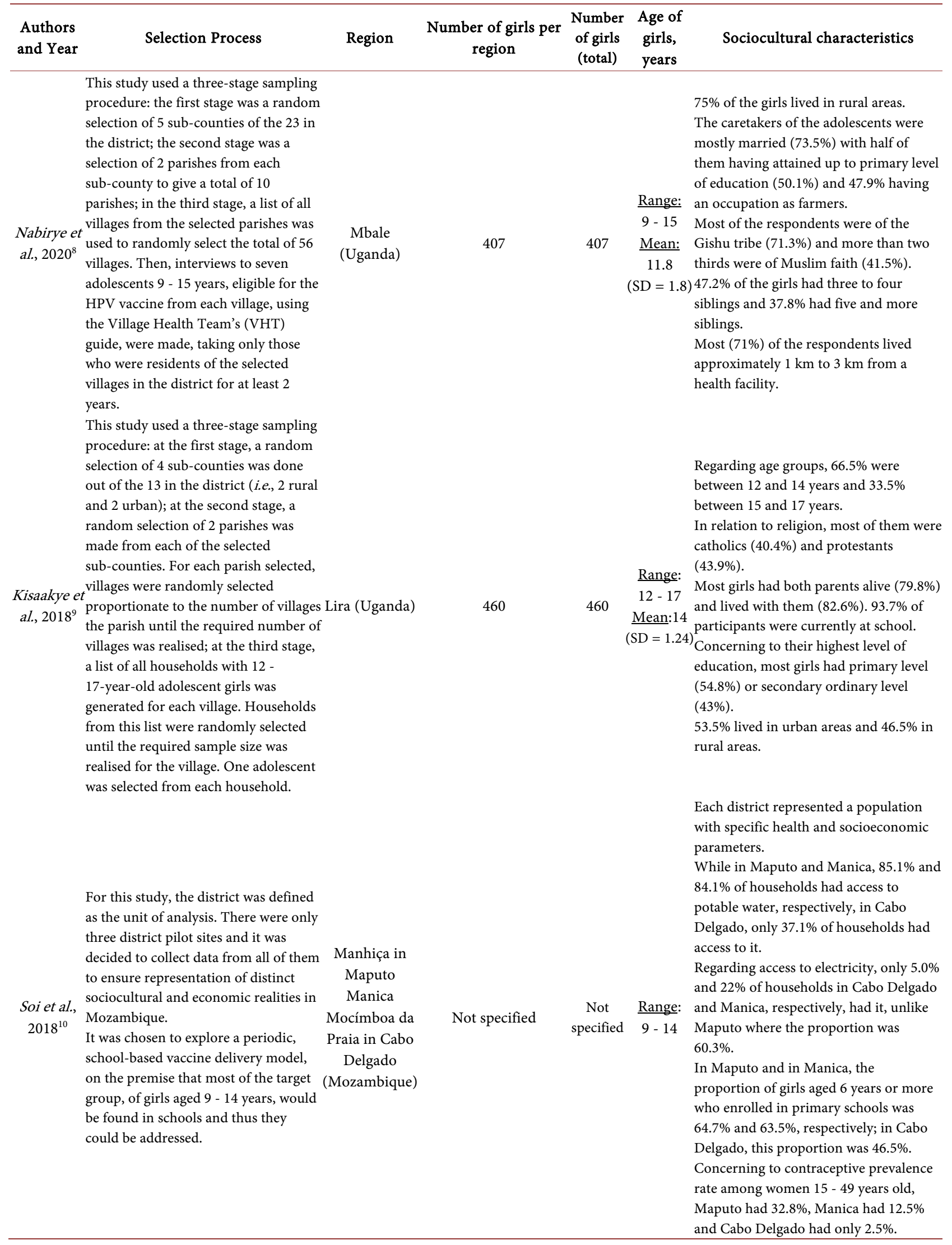




\section{Continued}

For inclusion in Gardasil Access

Program (GAP), interested

organizations and institutions completed a detailed application form to describe the characteristics of their institution and their related vaccination experience. The application collected information on the managing institution, vaccination implementation plan,

Ladner et estimated target population of girls, al., 2014 $4^{11}$ logistics, human and financial resources available to support the program, and health services provided by the institution implementing the program. For each program, the number of targeted girls was determined prior to implementation using available population, census and/or school enrollment data, among other sources.

This study used a convenience

Fregnani et sampling, since girls were included Barretos (Braal., $2013^{12}$ if their parents authorize the vaccine uptake.

Each program used different factors to determine the target population. Programs using health facility-based or mixed models utilized population data for the geographic area included in the campaign. Information on the number of

Ladner et inhabitants and number of girls al., 2012 $2^{13}$ included in the vaccination age range living in a specific geographic area was obtained used to calculate the target population for the vaccination program. Programs using school-based models based their target population calculation on the number and age of girls registered at participating schools.
Bhutan (2009) - 3200

Bolivia (2009) - 3480

Bolivia (2010) - 7500

Bolivia (2010) - 30,900

Bolivia Cambodia (2009) - 9600

Cambodia Cambodia (2010) - 2000

Cameroon Cameroon (2010)- 6400

Georgia Georgia (2010) - 6400

Kenya Honduras (2011) - 3200

Lesotho Honduras (2012) - 1575

Moldova Kenya (2011) - 3000

Nepal Lesotho (2009) - 40,000

Tanzania Lesotho (2010) - 40,100

Uzbekistan Nepal (2010) - 3000

Nepal (2011) - 10,000

Tanzania (2010) - 5532

Uganda (2010) - 985

Uzbekistan (2009) - 8450
Bhutan Bolivia (2011) - 50,000

Haiti Honduras Haiti (2009) - 3300

Uganda Moldova (2009) - 6934
Range: $9-13$
Not specified
The study population is a group of adolescents residing in Barretos, Brazil. It's a county in the State of São Paulo in Southeastern of Brazil, which is located approximately 230 miles from the State capital (road distance). The economy of Barretos is based on

Range: agriculture and the industrialization of 10 - 16 meat both for domestic and export 1574 1574 Mean: markets.

$11.931 \%$ of the parents and guardians of $(\mathrm{SD}=1.0)$ the target girls had a family income of US\$501 - 1000 and $26.9 \%$ of them had a family income of US\$201 - 500 . Regarding the education level, $40.3 \%$ of the parents and guardians of the girls had 9 - 11 years of study. $65.6 \%$ of them were Catholic and $98.3 \%$ lived in urban areas.
Bhutan (2009) - 3200

$\begin{array}{cc}\text { Bhutan Bolivia } & \text { Bolivia (2009) - 3480 } \\ \text { Bolivia (2010) - 30,900 }\end{array}$ Cambodia

Cameroon

Haiti Lesotho Nepal
Cambodia (2009) - 2000

Cameroon (2010) - 1600

Haiti (2009) - 3300

Lesotho (2009) - 40,100

Nepal (2010) - 3000
Range: $9-18$
Not specified 


\section{Continued}

For surveys in India, Peru and Uganda and for the first year in Viet Nam, a two-stage cluster sample design was used. The primary sampling cluster was the census district or census enumeration area within the prespecified geographical boundary of the vaccination programme. The secondary sampling unit was the household within each cluster. Each country's census department, with the exception of Peru's, drew the sample using recent data and provided a list of clusters and locations to the research team. In Peru, the research team randomly selected clusters after each available cluster within the

LaMon- geographical boundary of the tagne et al., programme was enumerated and $2011^{14}$ listed. The selection of households started at a central or randomly selected location in the cluster and progressed from house to house using the next-nearest-household approach. For the second year survey in Viet Nam, systematic random sampling from a complete census of all eligible households was used. The sample was drawn for each of the two vaccination strategies from three geographical areas in which the programme was implemented (i.e. six separate samples). A random number generator determined the starting point and the sampling interval and was applied to each list of households that contained girls eligible for vaccination.

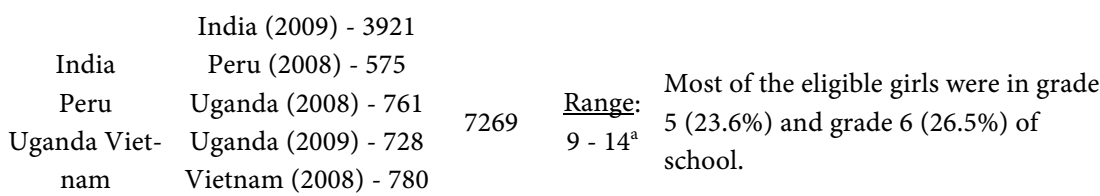

Range: Most of the eligible girls were in grade $9-14^{\mathrm{a}}$

$5(23.6 \%)$ and grade $6(26.5 \%)$ of school.

${ }^{a}$ Most of the girls in this article were between 9 and 14 years old, however there is a group of 102 girls who were included in this analysis but who were over 14 years old. The article does not refer to the maximum age found in girls in this age group ( $>14$ years old) so, as our systematic review includes an age range between 9 and 18 years old, this group will be included in our study in order to use the coverage data in this article.

Table 5. Results of the application of HPV vaccine, presented in percentage of coverage, in each study.

\begin{tabular}{|c|c|c|c|c|c|}
\hline $\begin{array}{l}\text { Authors } \\
\text { and Year }\end{array}$ & $\begin{array}{l}\text { Number of } \\
\text { girls per region }\end{array}$ & Measurement Method & $\begin{array}{l}\text { HPV Vaccine } \\
\text { type applied }\end{array}$ & $\begin{array}{l}\text { Vaccination } \\
\text { delivery model }\end{array}$ & $\begin{array}{c}\text { Coverage of } \\
\text { HPV vaccination (\%) }\end{array}$ \\
\hline $\begin{array}{l}\text { Nabirye et } \\
\text { al., } 2020^{8}\end{array}$ & 407 & $\begin{array}{l}\text { Uptake of the HPV vaccine } \\
\text { was measured by having a } \\
\text { vaccination card that indicates } \\
\text { the number of doses attained. }\end{array}$ & Cervarix $^{\circledR}$ & $\begin{array}{l}\text { School-based delivery } \\
\qquad(\mathrm{SB})^{\mathrm{a}}\end{array}$ & $13.8 \%(56 / 407)$ \\
\hline $\begin{array}{c}\text { Kisaakye et } \\
\text { al., } 2018^{9}\end{array}$ & 460 & $\begin{array}{l}\text { Through interviewer- } \\
\text { administered questionnaire, } \\
\text { uptake of HPV vaccine was } \\
\text { determined by using } \\
\text { respondents' recall or } \\
\text { vaccination cards if were } \\
\text { present. }\end{array}$ & Not specified & $\begin{array}{l}\text { School-based delivery } \\
\text { Health-centre-based } \\
\text { delivery }(\mathrm{HCB})^{\mathrm{b}} \\
\text { Mixed delivery }(\mathrm{M})^{\mathrm{c}}\end{array}$ & $17.6 \%(81 / 460)$ \\
\hline
\end{tabular}




\section{Continued}

\begin{tabular}{|c|c|c|c|c|c|}
\hline $\begin{array}{c}\text { Soi et al., } \\
2018^{10}\end{array}$ & Not specified & $\begin{array}{l}\text { In each school, one identified } \\
\text { responsible teacher was tasked } \\
\text { with registration of the } \\
\text { vaccination dates and took on } \\
\text { the role of filling in girls' } \\
\text { vaccination cards or } \\
\text { vaccination registration books. }\end{array}$ & Cervarix $^{\circledR}$ & School-based delivery & $\begin{array}{c}\text { Manhiça - 73.3\% } \\
\text { Manica - } 47 \% \\
\text { Mocímboa da Praia - 16\% }\end{array}$ \\
\hline $\begin{array}{l}\text { Ladner et } \\
\text { al., } 2014^{11}\end{array}$ & $\begin{array}{c}\text { Bhutan (2009) - 3200 } \\
\text { Bolivia (2009) - 3480 } \\
\text { Bolivia (2010) - 7500 } \\
\text { Bolivia (2010) - 30,900 } \\
\text { Bolivia (2011) - 50,000 } \\
\text { Cambodia (2009) - } 9600 \\
\text { Cambodia (2010) - } 2000 \\
\text { Cameroon (2010) - } 6400 \\
\text { Georgia(2010) - 6400 } \\
\text { Haiti (2009) - 3300 } \\
\text { Honduras (2011) - 3200 } \\
\text { Honduras (2012) - } 1575 \\
\text { Kenya (2011) - 3000 } \\
\text { Lesotho (2009) - 40,000 } \\
\text { Lesotho (2010)- 40,100 } \\
\text { Moldova (2009) - 6934 } \\
\text { Nepal (2010) - 3000 } \\
\text { Nepal (2011) - 10,000 } \\
\text { Tanzania (2010) - 5532 } \\
\text { Uganda (2010) - } 985 \\
\text { Uzbekistan (2009) - } 8450\end{array}$ & $\begin{array}{l}\text { Organizations and institutions } \\
\text { participating in GAP were } \\
\text { required to submit final } \\
\text { program reports once the } \\
\text { vaccination program had } \\
\text { completed administration of } \\
\text { all three doses of vaccine. }\end{array}$ & Gardasil $^{\circledR}$ & $\begin{array}{c}\text { School-based delivery } \\
\text { Health-centre-based } \\
\text { delivery } \\
\text { Mixed delivery }\end{array}$ & $\begin{array}{c}\text { Bhutan (2009) SB - 85.0\% } \\
\text { Bolivia (2009) SB - 107.4\% } \\
\text { Bolivia (2010) M - 73.5\% } \\
\text { Bolivia (2010) SB - 89.3\% } \\
\text { Bolivia (2011) SB - 88.1\% } \\
\text { Cambodia (2009) M - 77.8\% } \\
\text { Cambodia (2010) HCB - 101.4\% } \\
\text { Cameroon (2010) M - 90.6\% } \\
\text { Georgia(2010) HCB - 69.1\% } \\
\text { Haiti (2009) SB - 87.4\% } \\
\text { Honduras (2011) SB - 98.9\% } \\
\text { Honduras (2012) M - 93.5\% } \\
\text { Kenya (2011) HCB - 83.3\% } \\
\text { Lesotho (2009) SB - 92.6\% } \\
\text { Lesotho (2010) SB - 84.3\% } \\
\text { Moldova (2009) SB - 99.6\% } \\
\text { Nepal (2010) SB - 105.5\% } \\
\text { Nepal (2011) SB - 99.2\% } \\
\text { Tanzania (2010) SB - 76.1\% } \\
\text { Uganda (2010) HCB - 95.1\% } \\
\text { Uzbekistan (2009) HCB - 100\% } \\
\text { Total - 88.7\% }\end{array}$ \\
\hline 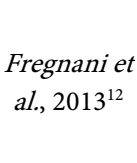 & 1574 & $\begin{array}{l}\text { Data were collected by the } \\
\text { vaccination team who applied } \\
\text { the HPV vaccine to the } \\
\text { targeted girls. }\end{array}$ & Gardasil $^{\circledR}$ & School-based delivery & 85\% (95\% CI: 80.5\% - 89.7\%) \\
\hline $\begin{array}{l}\text { Ladner et } \\
\text { al., } 2012^{13}\end{array}$ & $\begin{array}{c}\text { Bhutan (2009) - } 3200 \\
\text { Bolivia (2009) - } 3480 \\
\text { Bolivia (2010) - } 30900 \\
\text { Cambodia (2009) - } 2000 \\
\text { Cameroon (2010) - } 1600 \\
\text { Haiti (2009) - } 3300 \\
\text { Lesotho (2009) - } 40100 \\
\text { Nepal (2010) - 3000 }\end{array}$ & $\begin{array}{l}\text { Participating institutions were } \\
\text { required to submit a final } \\
\text { project report after completion } \\
\text { of the vaccination campaign ( } 3 \\
\text { doses of HPV vaccine). }\end{array}$ & Gardasil $^{\circledR}$ & $\begin{array}{c}\text { School-based delivery } \\
\text { Health-centre-based } \\
\text { delivery } \\
\text { Mixed delivery }\end{array}$ & $\begin{array}{c}\text { Bhutan (2009) SB - 85,0\% } \\
\text { Bolivia (2009) SB - 107.4\% } \\
\text { Bolivia (2010) M - 89.3\% } \\
\text { Cambodia (2009) HCB - 101.3\% } \\
\text { Cameroon (2010) HCB - 64.5\% } \\
\text { Haiti (2009) SB - } 87.4 \% \\
\text { Lesotho (2009) M - 84.3\% } \\
\text { Nepal (2010) M - 105.5\% } \\
\text { Total - 87.8\% }\end{array}$ \\
\hline $\begin{array}{l}\text { LaMon- } \\
\text { tagne et al., } \\
2011^{14}\end{array}$ & $\begin{array}{c}\text { India (2009) - } 3921 \\
\text { Peru (2008) - } 575 \\
\text { Uganda (2008) - } 761 \\
\text { Uganda (2009) - 728 } \\
\text { Vietnam (2008) - } 780 \\
\text { Vietnam (2009) - } 504\end{array}$ & $\begin{array}{l}\text { Data were collected using a } \\
\text { standardized structured } \\
\text { population-based } \\
\text { questionnaire adapted from } \\
\text { the WHO infant } \\
\text { immunization survey. They } \\
\text { were carried out } 1 \text { to } 3 \text { months } \\
\text { after administration of the } \\
\text { third vaccine dose. }\end{array}$ & Not specified & $\begin{array}{c}\text { School-based delivery } \\
\text { Health-centre-based } \\
\text { delivery }\end{array}$ & $\begin{array}{c}\text { Urban India (2009) M - 77.2\% } \\
\text { Rural India (2009) M - 87.8\% } \\
\text { Tribal India (2009) M - 83.9\% } \\
\text { Peru (2008) SB -82.6\% } \\
\text { (95\% CI: 79.3 - 85.6) } \\
\text { Uganda (2008) SB - 90.5\% } \\
\text { Uganda (2009) SB - 88.9\% } \\
\text { (95\% CI: 84.7 - 92.4) } \\
\text { Vietnam (2008) SB - 83.0\% } \\
\text { (95\% CI: 77.6 - 87.3) } \\
\text { Vietnam (2009) SB - 96.1\% } \\
\text { (95\% CI: 93.0 - 97.8) } \\
\text { Vietnam (2008) HCB - 93.9\% } \\
\text { Vietnam (2009) HCB - 98.6\% } \\
\text { (95\% CI: 95.7 - 99.6) }\end{array}$ \\
\hline
\end{tabular}

a In a school-based delivery model, the vaccination sites used are schools attended by the target population. ${ }^{b}$ In a health-centre-based delivery model, the vaccination sites used are health facilities attended by the target population. 'In a mixed delivery model, the vaccination sites used are schools as well as health facilities attended by the target population. 
Table 6. Results concerning the challenges in HPV vaccine implementation in each study.

\begin{tabular}{|c|c|c|c|}
\hline $\begin{array}{c}\text { Authors and } \\
\text { Year }\end{array}$ & $\begin{array}{l}\text { Number of } \\
\text { girls per region }\end{array}$ & Measurement Method & Main challenges in HPV vaccine implementation \\
\hline $\begin{array}{l}\text { Nabirye et al., } \\
2020^{8}\end{array}$ & 407 & $\begin{array}{l}\text { Health system factors were } \\
\text { assessed through key informant } \\
\text { interviews and an observation } \\
\text { checklist. Six key informant } \\
\text { interviews with the district } \\
\text { health team members who had } \\
\text { an expert opinion about the } \\
\text { health services factors that } \\
\text { influence uptake of HPV } \\
\text { vaccination in the district were } \\
\text { conducted. }\end{array}$ & $\begin{array}{l}\text { Factors associated with uptake of the HPV vaccine: } \\
\text { 1) Lack of awareness about the HPV vaccine, the number of doses } \\
\text { that they must receive and the schedule or interval of the vaccines - } \\
\text { 45\% (182/348) of the adolescents who had either received either one } \\
\text { dose or none; } \\
\text { 2) Reluctance to vaccinate, being afraid of vaccines and myths about } \\
\text { the vaccines - 17.5\% (61/348) } \\
\text { 3) Distance to health facility - 14.4\% (50/348); } \\
\text { 4) Lack of money - 10\% ( } 35 / 348) \text {; } \\
\text { 5) Receiving the vaccine from static sites and not from outreach } \\
\text { clinics; } \\
\text { 6) Not receiving an explanation on the possible side effects of the } \\
\text { HPV vaccine; } \\
\text { 7) Not receiving the vaccines alongside other services; } \\
\text { 8) Not having many options from where to receive the HPV } \\
\text { vaccine. } \\
\text { Barriers to service delivery: } \\
\text { 1) Low financing; } \\
\text { 2) Myths about the vaccine; } \\
\text { 3) Unclear communication on the target for the vaccine's } \\
\text { coverage; } \\
\text { 4) Transport challenges to reach the adolescents in the } \\
\text { community; } \\
\text { 5) Inequity in access for those who prefer utilize private health } \\
\text { facilities and for girls in private schools, because private schools and } \\
\text { private health facilities are not given the HPV vaccine; } \\
\text { 6) Difficulties in the vaccine delivery in Health-centre-based } \\
\text { delivery compared to School-based delivery due to the target groups } \\
\text { not being evident. } \\
\text { Barriers for human resources for health: } \\
\text { 1) Inadequate staff to run the work in the health center; } \\
\text { 2) Insufficient training among health workers about the vaccines; } \\
\text { Barriers to vaccines, supplies and medicines: } \\
\text { 1) Inconsistency in vaccine supply; } \\
\text { 2) Lack of integration of the HPV vaccines with other services. }\end{array}$ \\
\hline $\begin{array}{c}\text { Kisaakye et al., } \\
2018^{9}\end{array}$ & 460 & $\begin{array}{l}\text { They conducted five key } \\
\text { informant interviews with the } \\
\text { district health team members } \\
\text { who had an expert opinion } \\
\text { about the health service factors } \\
\text { that influence uptake of HPV } \\
\text { vaccination in Lira district. }\end{array}$ & $\begin{array}{l}\text { Factors associated with uptake of the HPV vaccine: } \\
\text { 1) Poor knowledge about the HPV vaccine ( } 56.09 \%, 258 / 460) \text {; } \\
\text { 2) Attained an education level of primary and below; } \\
\text { 3) Negative attitudes towards the HPV vaccine; } \\
\text { 4) Receiving all the HPV vaccine doses from one vaccination site; } \\
\text { 5) Not been recommended or encouraged by a health worker to go } \\
\text { for the HPV vaccine; } \\
\text { 6) Not been encouraged by a village health team member (VHT); } \\
\text { 7) Not receiving full information about the HPV vaccination. } \\
\text { Barriers to vaccine delivery and supplies: } \\
\text { 1) HPV vaccine community outreaches were not conducted in the } \\
\text { residences of the targeted girls; } \\
\text { 2) Unavailability of vaccine at all visits; } \\
\text { 3) Lack of sufficient funds to facilitate the transport/delivery of } \\
\text { vaccines at the different vaccination sites and the health workers } \\
\text { responsible for vaccinating the girls. }\end{array}$ \\
\hline
\end{tabular}


Soi et al., $2018^{10}$ Not specified
Bhutan (2009) - 3200

Bolivia (2009) - 3480

Bolivia (2010) - 7500

Bolivia (2010) - 30,900

Bolivia (2011) - 50,000

Cambodia (2009) - 9600

Cambodia (2010) - 2000

Cameroon (2010) - 6400

Georgia (2010) - 6400

Haiti (2009) - 3300

Ladner et al., $2014^{11}$
Honduras (2011) - 3200

Honduras (2012) - 1575

Kenya (2011) - 3000

Lesotho (2009) - 40,000

Lesotho (2010) - 40,100

Moldova (2009) - 6934

Nepal (2010) - 3000

Nepal (2011) - 10,000

Tanzania (2010) - 5532

Uganda (2010) - 985

Uzbekistan (2009) - 8450
Development of a semi structured interview guide to capture information on the selected CFIR constructs and used it to conduct $40 \mathrm{key}$ informant interviews (KIIs) the Ministry of Health (MOH) central level and all three demonstration districts
Factors associated with uptake of the HPV vaccine:

1) Little access to knowledge and poor information given by teachers for lack of training;

2) Exclusion of the opinion of important religious leaders in the community;

3) Mistrust and misbeliefs regarding the target population for vaccination.

\section{Barriers to service delivery:}

1) Implementation of the HPV vaccine predominantly out of health facilities, because health workers had to rely on non-health workers, teachers in school-based and community leaders in community based vaccination;

2) Unclear roles and duties in the context of multiple implementing entities;

3) Lack of knowledge of the exact location of girls who were not in school;

4) Vaccination date scheduled during a local public holiday;

5) The lower socioeconomic development of these low-income districts and the underlying poor state of the transportation network;

6) Few number of schools in low-performing district and at further distances from health facilities, resulting in a higher number of girls unenrolled in school and in increased travel time for school-based vaccination efforts;

7) Insufficient financial resources, organizational incentives and rewards, including lack or insufficient funding by key stakeholders; 8) Lack of learning climate (extent to which evaluation is integrated in demonstration project), which leads to lack of interest in improving coverage.

\section{Barriers to service delivery:}

1) Programs managed by Ministries of Health $(\mathrm{MoH})$ due to more internal bureaucratic hurdles;

2) Lack of community sensitization about the availability and value of vaccinating school-aged girls against HPV;

3) Lack of community involvement in following-up with girls participating in the vaccination campaign;

4) Lack of key messages about the safety and efficacy of the vaccine at the launch of a vaccine campaign ;

Organizations and institutions 5) Long-term vaccination programs, mainly longer interval between participating in GAP were re- vaccine shipment and administration of the doses, that reflects quired to submit final program difficulty in vaccinating girls against HPV in a timely manner; reports. These reports gathered 6) Difficulties in conducting effective cost analyses around HPV financial data (if available) and vaccination in low and middle-income countries due to costs information related to commu- associated to financing of pre-introduction activities, development nity involvement actions, com- of new delivery infrastructure and the deployment of new human munication key messages and resources or reallocation of existing personnel; methods.

7) Loss of interest in completing all three doses of vaccine among girls and their parents due to the lack of momentum within a given program;

8) Lower effectiveness in Health-centre-based delivery compared to School-based delivery, because daily attendance of target girls at school allows them to be vaccinated more quickly than might occur at a health clinic that requires the girl to make a special trip; Lack of information disseminated by schools, that is more important than information provided by local media with respect to vaccine uptake. 


\section{Continued}

Fregnani et al., $2013^{12}$

1574

Bhutan (2009) - 3200 Bolivia (2009) - 3480

Bolivia (2010) - 30,900

Ladner et al., Cambodia (2009) - 2000 2012 ${ }^{13} \quad$ Cameroon (2010) - 1600 Haiti (2009) - 3300 Lesotho (2009) - 40,100 Nepal (2010) - 3000

India (2009) - 3921

Peru (2008) - 575

LaMontagne et al., $2011^{14}$

Uganda (2008) - 761
Uganda (2009) - 728

Vietnam (2008) - 780

Vietnam (2009) - 504
The parents or legal guardians filled out a questionnaire.

Factors associated with uptake of the HPV vaccine:

Reasons given by the parents and guardians for refusing to participate in the vaccination program (responders could report more than one reason):

1) Fear of adverse events (27.4\%);

2) Undisclosed personal reasons (20.2\%);

3) The girl doesn't want to receive the vaccine shot (14.5\%);

4) Belief that the girl was too young $(9.7 \%)$;

5) Girl has a health problem (9.7\%);

6) Belief that the vaccine is not necessary $(8.9 \%)$;

7) Incorrect information about the vaccine (6.5\%);

8) Physician (pediatrician/gynecologist) advise against it (5.6\%);

9) Does not want to participate in a research study (4.0\%);

10) No trust in vaccine efficacy $(2.4 \%)$;

11) Difficulties travelling to the hospital to get the vaccine (1.6\%).

Factors associated with uptake of the HPV vaccine:

1) Lack of explanation of basic information on cervical cancer in very plain language;

For the qualitative analysis, 2) Lack of more in-depth discussion sessions with parents and textual data were extracted from caregivers and evaluation of the knowledge of and attitudes toward application forms and progress HPV vaccination in these audiences.

reports and then indexed. This Barriers to service delivery:

enabled the generation of 1) Low number of vaccination sites and lack of administration sites specific analytical categories. easily accessible;

Qualitative data on a variety of 2) The lower effectiveness of Health-centre-based delivery indicators were systematically compared to School-based delivery;

collected and analyzed for each 3) Lack of specific resources allocated to sensitize and train program in the form of field schoolteachers to assist in recruitment of and follow-up with girls notes and transcripts. The

analysis was conducted during HPV vaccination campaigns;

4) Lack of variety of communication vehicles like community according to the three defined delivery models.

meetings informational posters, flyers, television, radio and newspapers;

5) Lack of community involvement, important for the definition of key messages, recruitment of participants and follow-up with participants.

Factors associated with uptake of the HPV vaccine:

1) Reason for partial or non-vaccination: school absenteeism.

Reasons for accepting or not accepting vaccination were assessed using an open-ended question without prompting a response. A respondent was any adult who could respond accurately to survey questions, but the parents were preferred.

2) Programme-related issues: not aware of the program; difficulty to determine eligibility.

3) Vaccine-related issues: concerns about safety; vaccine is new; vaccine is experimental; impact on fertility; insufficient information about the vaccine; fear of injections; do not believe vaccine is good for health; allergic to vaccines; followed the advice of others.

\section{Barriers to service delivery:}

1) Being absent from school on the vaccination day;

2) Insufficient information about cervical cancer, the HPV vaccine or the HPV vaccination programme;

3) Lack of community sensitization.

distinct lessons learnt from different countries experiences. We would like to believe that the results of this systematic review presented here could contribute to support Public Health Authorities from low and middle-income countries to apply the HPV vaccine at national level in an organized and efficient manner. The findings published in the studies we analyzed clearly demonstrate that only in 
this way it becomes possible to overpass the barriers and inequalities in the women's access to the important health interventions. Indeed, until 2017, forty-three developing countries have acquired experience in delivering the HPV vaccine to adolescent girls through pilot programs, demonstration programs and national introductions of vaccination programmes [3]. Although more developing countries have currently adopted the implementation of the vaccination, developed countries still represent the paradigm of HPV vaccine adoption as a means of primary prevention of cervical carcinoma and remain the majority of settings that included HPV vaccine in their national program [6]. Paradoxically, despite of having limited access, many of the lower-resources countries reached higher coverage rates than some of the richer countries, including France, USA, Japan or Denmark that have struggled to achieve even 50\% coverage [6]. Our study found that the mean coverage rate of Ladner et al. [11], that assessed 21 programs of 14 developing different countries, was 88.7\%; in Ladner and colleagues [13], which evaluated 8 programs in 7 countries, the rate was similar, reaching to $87.8 \%$. Regarding Manhiça, a county from Mozambique [10], a rate of $73.3 \%$ of coverage was achieved; finally, Fregnani et al. [12] showed that in Barretos county, Brazil, the coverage rate was $85 \%$ after the implementation of a vaccination program. These results combined are in accordance with findings from Gallagher and co-workers [6], in which the majority of small-scale pilots and demonstration projects achieved $70 \%-90 \%$ coverage with the 2 or 3 dose schedule, and four national programs in low and middle-income countries had $80 \%-90 \%$ of the adolescents targeted receiving at least one dose of the vaccine. Likewise, in Gallagher et al. [5], 33 developing countries reached more than 50\% final dose coverage and almost half (42\%) reported $90 \%$ or higher coverage. Conversely, such high coverage rates weren't found in the two studies from Uganda or in the other two African regions of the study of Mozambique, which the results were below 50\%. These discrepancies in vaccination coverage rates between different developing countries are yet to be better explained. Nevertheless, the good news is that coverage of $100 \%$ is not needed to have a significant impact on HPV incidence and mortality, since this can be achieved with coverage even lower than $40 \%$ [6]. The success of vaccination implementation on a national level, measured by high coverage rate, rely fundamentally on the capacity of developing countries to apply the knowledge and experience gathered by others that have already implemented with positive results [3]. To do that, it's necessary to recognize the barriers and challenges that compromise the vaccination. The main difficulties identified by all the studies we analyzed were lack of knowledge of the population, insufficient financial means and issues concerning delivery models, health professionals and vaccine supplies.

Regarding knowledge, the principal problems were lack of awareness about HPV and vaccine due to lack of properly education and discussion with girls and their parents or guardians. Consequently, from that arise uncertainty, misbeliefs, worries and myths that can undermine the success of the vaccination programs [10] [14]. Beside that it's important that, when given, the information is clear, 
with plain and accessible language as anticipated by Wigle and colleagues [15].

Financial problems are also critical in various aspects, namely in the start of the implementations, their success and the capacity to evolve into national immunization programs. The lower socioeconomic development of developing countries and the lack of funds to financing pre-introduction activities, development of new delivery infrastructure and the deployment of human resources or reallocation of existing personnel were the relevant points addressed in the articles included in this review. All these aspects were stated by Gallagher K.E. et al. [6], which highlights the idea that the co-financing resources are insufficient, so these countries have to make decisions based on priorities, ending up to postpone the HPV vaccine introduction. The reality is that total costs and proportion spent in different components of the programs varied widely between countries, so it isn't possible to assume exactly how much the HPV vaccine implementation will cost, according to LaMontagne et al. [3]. Thus, one of the major concerns of policy makers of the developing countries is the fact that HPV vaccine programs may be expensive and unsustainable [6].

Concerning delivery models, the school-based one appears to have higher effectiveness compared to the health-center-based model, even with the need of integration of the health and education systems. This model optimizes the vaccination coverage rate, because girls with age ranges recommended for the vaccine are likely to attend school, so it's easier to vaccinate than might occur at health clinics. This finding is in agreement with Gallagher et al. [6] and Gallagher et al. [16], which refer that school-based delivery strategies with some specific mobilization to reach out-of-school girls should be the predominant model chosen to reach high coverage rate. The only aspect that came into conflict was the fact that Ladner et al. [13] found that mixed models were more effective than school-based ones unlike Ladner et al. [11]. As this article contains a larger number of programs and population and concludes the same as other reviews, it is more likely that its results are more reliable.

Lack of sufficient human resources and appropriate training in implementing the interventions are also a challenge. Insufficient vaccine supplies are likewise a serious question because of the current increasing demands. Actually, due to the inability to meet the demands of 2020 and 2021, some Gavi-eligible countries have to postpone multi-age vaccinations so other countries can start the single-age vaccination [17].

Lastly, a challenge that wasn't addressed in our search but that Wigle et al., [15] refers and that compromises the successful implementation of the intervention is the lack of political will and commitment to new health technologies.

All these findings were based in a collection of articles, mostly classified with a moderate quality. The general problems encountered during the analysis, both from observational and cross-sectional studies specifically, relate to confounders not being addressed or clearly defined and poor description of the statistical methods used to analyze data. Beyond that, other limitations were present in 
these studies. The first limitation relates to the type of study itself, since a cross-sectional design limits the possibility of making causal inferences about the main outcome and independent variables. The use of census information is an imprecise methodology that can induce errors in determining target population, which can impact the coverage rates calculated. Indeed, percentages greater than $100 \%$ encountered in some programs indicate an under-estimation of the target population and/or recruitment of girls from outside of the original target area, suggesting that methodologies used for determining the target population may be suboptimal. In these studies, there may be a loss of representativeness of population and inability to generalize onto a national level in terms of results of the coverage and involved expenses, because the programs were implemented in specific regions of the countries. Finally, the use of questionnaires and open-ended questions give rise to possible poor recall of information and misclassification of the responses achieved by the investigators, respectively. Likewise, this review has some limitations. One of them is the fact that only English language was included, which may have eliminated potentially important studies in other languages. Missing data related to the study population (total number and sociocultural characteristics) and distinct measurement methods between studies can also limited the interpretation and comparison of the results.

The main challenges we found in several publications can be briefly resumed as a permissive combination of lack of information of the population, prejudice regarding the vaccine being linked to a sexually transmitted agent, inflexible cultural and religious values, lack of adequate infrastructure and medical care, lack of financial resources for the introduction and proper maintenance of vaccination, and lack of medical surveillance of periodic monitoring and well-organized preventive care of risk group women.

\section{Conclusions}

In conclusion, the introduction of a primary prevention as HPV vaccine has a remarkable impact on the burden of cervical cancer, specifically in developing countries where screening and treatment are non-existent or limited. To achieve a successful implementation of vaccination programs, it's obviously necessary robust financial resources, strong and responsible political determination and efficient strategy to reach the target population and trace the outcomes. It's also required tailoring specific interventions to meet the needs, because in public health care, with huge divergent cultural backgrounds, Public Health authorities must face challenges and observe the priorities of each region. In reality, regarding health interventions, one size doesn't fit all. Actually, the common barrier among developing countries to implement HPV vaccination seems to be related to the underserved medical assistance and economic governmental support, as well as, the substantial lack of information of the population, maybe related to illiteracy or low schooling pattern of the majority of women, mainly those living in remote areas. Therefore, in the future, it will be essential that more developing 
countries have access and opportunity to implement the vaccine and discuss the possible solutions for these challenges. It would be beneficial as well to conduct studies that analyze the coverage rates of the countries after the elimination of the barriers and the repercussions on the mortality rates, to assess if they are as important as they seem.

The adoption of a vaccination system in poor and developing countries must, first of all, rely on the formal commitment of the health authorities and the categorical commitment of the political agents in each region. Preserving the health of a population is, before a medical act, a political commitment. Any effort that is made without the support of the political agents of a country seems doomed to fail, as they will not resist the advance of time. Disease prevention may have a start day, but it must not have an end date.

\section{Conflicts of Interest}

The authors declare no conflicts of interest regarding the publication of this paper.

\section{References}

[1] World Health Organization (2019) Human Papillomavirus (HPV) and Cervical Cancer.

https://www.who.int/news-room/fact-sheets/detail/human-papillomavirus-(hpv)-an d-cervical-cancer

[2] Arbyn, M., Weiderpass, E., Bruni, L., Sanjosé, S., Saraiya, M., Ferlay, J. and Bray, F. (2020) Estimates of Incidence and Mortality of Cervical Cancer in 2018: A Worldwide Analysis. The Lancet Global Health, 8, e191-e203. https://doi.org/10.1016/S2214-109X(19)30482-6

[3] Lamontagne, D.S., Bloem, P.J., Brotherton, J.M., Gallagher, K.E., Badiane, O. and Ndiaye, C. (2017) Progress in HPV Vaccination in Low- and Lower-Middle-Income Countries. International Journal of Gynecology \& Obstetrics, 138, 7-14. https://doi.org/10.1002/ijgo.12186

[4] Expanded Programme on Immunization (EPI) of the Department of Immunization, Vaccines and Biologicals of World Health Organization (2016) Guide to Introducing HPV Vaccine into National Immunization Programmes.

[5] Gallagher, K.E., Howard, N., Kabakama, S., Mounier-Jack, S., Burchett, H.E., Lamontagne, D.S. and Watson-Jones, D. (2017) Human Papillomavirus (HPV) Vaccine Coverage Achievements in Low and Middle-Income Countries 2007-2016. Papillomavirus Research, 4, 72-78. https://doi.org/10.1016/j.pvr.2017.09.001

[6] Gallagher, K., Lamontagne, D. and Watson-Jones, D. (2018) Status of HPV Vaccine Introduction and Barriers to Country Uptake. Vaccine, 36, 4761-4767. https://doi.org/10.1016/j.vaccine.2018.02.003

[7] (2015) PRISMA Transparent Reporting of Systematic Reviews and Meta-Analyses. PRISMA Flow Diagram. http://prisma-statement.org/PRISMAStatement/FlowDiagram

[8] Nabirye, J., Okwi, L., Nuwematsiko, R., Kiwanuka, G., Muneza, F., Kamya, C.N. and Babirye, J. (2020) Health System Factors Influencing Uptake of Human Papilloma Virus (HPV) Vaccine among Adolescent Girls 9-15 Years in Mbale District, Uganda. BMC Public Health, 20, Article No. 17. 
https://doi.org/10.1186/s12889-020-8302-Z

[9] Kisaakye, E., Namakula, J., Kihembo, C., Kisakye, A., Nsubuga, P. and Babirye, J.N. (2018) Level and Factors Associated with Uptake of Human Papillomavirus Infection Vaccine among Female Adolescents in Lira District, Uganda. Pan African Medical Journal, 31, 184. https://doi.org/10.11604/pamj.2018.31.184.14801

[10] Soi, C., Gimbel, S., Chilundo, B., Muchanga, V., Matsinhe, L. and Sherr, K. (2018) Human Papillomavirus Vaccine Delivery in Mozambique: Identification of Implementation Performance Drivers Using the Consolidated Framework for Implementation Research (CFIR). Implementation Science, 13, 151. https://doi.org/10.1186/s13012-018-0846-2

[11] Ladner, J., Besson, M., Rodrigues, M., Audureau, E. and Saba, J. (2014) Performance of $21 \mathrm{HPV}$ Vaccination Programs Implemented in Low and Middle-Income Countries, 2009-2013. BMC Public Health, 14, Article No. 670. https://doi.org/10.1186/1471-2458-14-670

[12] Fregnani, J.H.T.G., Carvalho, A.L., Eluf-Neto, J., Ribeiro, K.d.C.B., Kuil, L.d.M., et al. (2013) A School-Based Human Papillomavirus Vaccination Program in Barretos, Brazil: Final Results of a Demonstrative Study. PLoS ONE, 8, e62647. https://doi.org/10.1371/journal.pone.0062647

[13] Ladner, J., Besson, M.-H., Hampshire, R., Tapert, L., Chirenje, M. and Saba, J. (2012) Assessment of Eight HPV Vaccination Programs Implemented in Lowest Income Countries. BMC Public Health, 12, Article No. 370. https://doi.org/10.1186/1471-2458-12-370

[14] Lamontagne, D.S., Barge, S., Le, N.T., Mugisha, E., Penny, M., Gandhi, S. and Jumaan, A. (2011) Human Papillomavirus Vaccine Delivery Strategies That Achieved High Coverage in Low- and Middle-Income Countries. Bulletin of the World Health Organization, 89, 821-830. https://doi.org/10.2471/BLT.11.089862

[15] Wigle, J., Coast, E. and Watson-Jones, D. (2013) Human Papillomavirus (HPV) Vaccine Implementation in Low and Middle-Income Countries (LMICs): Health System Experiences and Prospects. Vaccine, 31, 3811-3817. https://doi.org/10.1016/j.vaccine.2013.06.016

[16] Gallagher, K.E., Howard, N., Kabakama, S., Mounier-Jack, S., Griffiths, U.K., Feletto, M. and Watson-Jones, D. (2017) Lessons Learnt from Human Papillomavirus (HPV) Vaccination in 45 Low- and Middle-Income Countries. PLoS ONE, 12, e0177773. https://doi.org/10.1371/journal.pone.0177773

[17] PATH (2020) Supporting Countries to Introduce the HPV Vaccine. https://path.org/articles/supporting-countries-introduce-hpv-vaccine 


\section{Appendix}

\section{Strobe checklist}

\section{Checklist for observational studies (combined)}

1a) Indicate the study's design with a commonly used term in the title or the abstract? 1b) Provide in the abstract an informative and balanced summary of what was done and what was found? 2) Explain the scientific background and rationale for the investigation being reported? 3) State specific objectives, including any prespecified hypotheses? 4) Present key elements of study design early in the paper? 5) Describe the setting, locations, and relevant dates, including periods of recruitment, exposure, follow-up, and data collection? 6a) Cohort study-Give the eligibility criteria, and the sources and methods of selection of participants? Describe methods of follow-up?; Case-control study-Give the eligibility criteria, and the sources and methods of case ascertainment and control selection? Give the rationale for the choice of cases and controls?; Cross-sectional study-Give the eligibility criteria, and the sources and methods of selection of participants? 6b) Cohort study-For matched studies, give matching criteria and number of exposed and unexposed?, Case-control study-For matched studies, give matching criteria and the number of controls per case?; 7) Clearly define all outcomes, exposures, predictors, potential confounders, and effect modifiers? Give diagnostic criteria, if applicable?; 8) For each variable of interest, give sources of data and details of methods of assessment (measurement), describe comparability of assessment methods if there is more than one group?; 9) Describe any efforts to address potential sources of bias?; 10) Explain how the study size was arrived at?; 11) Explain how quantitative variables were handled in the analyses. If applicable, describe which groupings were chosen and why?; 12a) Describe all statistical methods, including those used to control for confounding?; 12b) Describe any methods used to examine subgroups and interactions?; 12c) Explain how missing data were addressed?; 12d) Cohort study-If applicable, explain how loss to follow-up was addressed?, Case-control study-If applicable, explain how matching of cases and controls was addressed?, Cross-sectional study-If applicable, describe analytical methods taking account of sampling strategy?; 12e) Describe any sensitivity analyses?; 13a) Report numbers of individuals at each stage of study - eg numbers potentially eligible, examined for eligibility, confirmed eligible, included in the study, completing follow-up, and analyzed?; 13b) Give reasons for non-participation at each stage?; 13c) Consider use of a flow diagram?; 14a) Give characteristics of study participants (eg demographic, clinical, social) and information on exposures and potential confounders?; 14b) Indicate number of participants with missing data for each variable of interest?; 14c) Cohort study-Summarize follow-up time (eg, average and total amount)?; 15) Cohort study-Report numbers of outcome events or summary measures over time?, Case-control study-Report numbers in each exposure category, or summary measures of exposure?, Cross-sectional study-Report numbers of outcome events or summary measures?; 16a) Give unadjusted esti- 
mates and, if applicable, confounder-adjusted estimates and their precision (eg, 95\% confidence interval)? Make clear which confounders were adjusted for and why they were included?; 16b) Report category boundaries when continuous variables were categorized?; 16c) If relevant, consider translating estimates of relative risk into absolute risk for a meaningful time period?; 17) Report other analyses done-eg analyses of subgroups and interactions, and sensitivity analyses?; 18) Summarize key results with reference to study objectives?; 19) Discuss limitations of the study, taking into account sources of potential bias or imprecision? Discuss both direction and magnitude of any potential bias?; 20) Give a cautious overall interpretation of results considering objectives, limitations, multiplicity of analyses, results from similar studies, and other relevant evidence?; 21) Discuss the generalizability (external validity) of the study results?; 22) Give the source of funding and the role of the funders for the present study and, if applicable, for the original study on which the present article is based? 